\title{
THERMODINAMIC PARAMETERS ON THE SORPTION OF PHOSPHATE IONS BY MONTMORILLONITE
}

\author{
Jaslin Ikhsan*, Endang Wijayanti, dan Sunarto \\ Jurusan Pendidikan Kimia, Fakultas MIPA, Universitas Negeri Yogyakarta, Karangmalang, Yogyakarta, 55281 \\ *email: jikhsan@ymail.com
}

diterima 1 Desember 2014, disetujui 3 Maret 2015

\begin{abstract}
The sorption of phosphate by montmorillonite at 10,30 , and $50{ }^{\circ} \mathrm{C}$ were investigated aiming to mainly determine thermodynamic parameters for the formation of surface complexes in the adsorption of phosphate ions by montmorillonite. Data were collected by adsorption edge experiments investigating the effect of $\mathrm{pH}$, adsorption isotherms enabling the effect of sorbate concentration, and acid-base titration calculating protons released or taken up by adsorption process. Data analysis was carried out using surface complexation model to fit the data collected in this study using the parameters obtained from previous study, as well as to calculate the values of $\Delta \mathrm{H}$ and $\Delta \mathrm{S}$. Previous study reported that phosphate ions formed two outer-sphere surface complexes with active sites of montmorillonite through hydrogen bonding. In the first complex, $\left[(\mathrm{XH})^{0}-\mathrm{H}_{2} \mathrm{~L}^{-}\right]^{-}$, the phosphate was held to permanent-charge $\mathrm{X}^{-}$sites on the tetrahedral siloxane faces, and the second complex, $\left[\left[\left(\mathrm{SO}^{-}\right)(\mathrm{SOH})\right]^{-}-\left[\mathrm{H}_{2} \mathrm{~L}\right]^{-}\right]^{2-}$ was formed through the interaction between the phosphate and variable charge surface hydroxyl groups at the edges of montmorillonite crystals and on the octahedral alumina faces. The values of $\Delta \mathrm{H}$ for the first and second reactions are 39.756 and $3.765 \times 10^{-7} \mathrm{~kJ} \mathrm{~mol}^{-1}$ respectively. Since both reactions have positive enthalpy values, it can be concluded that the reactions are endothermic. Large energy for the first reaction is needed by $\mathrm{X}^{-}$sites (permanent negatively charge sites of montmorillonite) to be partially desolvated, on which $\mathrm{K}^{+}$or other surface cations are replaced by $\mathrm{H}^{+}$ions in the surface protonated process, and are then ready to interact phosphate ions in the solution. Small values of $\Delta \mathrm{H}$ for the second reactions indicates that hydrogen bonds formed by phosphate and $\mathrm{SOH}$ sites in the second reaction are easily broken out, and the phosphate can easily desorbed from the surface. The values of $\Delta \mathrm{S}$ for the first and second reactions are 122.523 and $2.393 \times 10^{-2} \mathrm{~J} \mathrm{~K}^{-1} \mathrm{~mol}^{-1}$, which are greater than $-10 \mathrm{~kJ} \mathrm{~mol}^{-1}$ and indicates that the surface reactions occurs through dissociative mechanisms.
\end{abstract}

Keywords: montmorillonite, adsorption edge, extended constant capacitance, surface complexation model, enthalpy, reaction mechanisms

\section{Introduction}

The excess of phosphate can decrease water quality because of the decrease of oxygendissolved concentration. It can cause water creatures suffer and even die, and results in imbalance of water ecosystem. There are many methods to reduce phosphate excess in the soil and water. One of the methods is adsorption.

In the adsorption, temperature is one of factors that affect significantly adsorption process. It is reported that temperature can change characteristics of adsorption process by changing basic elements of a system, such as chemical properties of sorbate/sorbent, surface charges of sorbent, and adsorption reaction kinetics [1-4].

By studying the effect of temperature in the sorption system, Detail information about surface chemistry of the adsorption system can be obtained, by which researcher en able to control the thermodynamic system of the adsorption process. Adsorption process in different temperatures is always related to enthalpy $(\Delta \mathrm{H})$ and entropy $(\Delta S) . \Delta H$ is total energy that involves in the adsorption process, whereas $\Delta \mathrm{S}$ shows uncertainty in the system in which the higher the entropy, the higher the uncertainty.

The strength of the bond between sorbate and sorbent in the adsorption can be seen from $\Delta \mathrm{H}$ values of the adsorption. If the $\Delta \mathrm{H}$ involved in the adsorption is between -10 and $-40 \mathrm{~kJ} / \mathrm{mol}$, the interaction between sorbate and sorbent is weak, called physisorption. In physisorption, interaction amongst the sorbate themselves is stronger than interaction between sorbate and sorbent. Physisorption process is always exothermic with small $\Delta \mathrm{H}$ values. On the other hand, if the adsorption involves $\Delta \mathrm{H}$ with the amount between -40 and $-100 \mathrm{~kJ} / \mathrm{mol}$, the interaction for surface complex formation is by stronger chemical bond, called chemisorption [5].

By varying temperature in the adsorption system, and modeling experimental data, the equilibrium constants of surface reactions as the 
function of temperature can be obtained. If temperature affect significantly to the adsorption, therefore the variation of temperature in an adsorption process will produce different equilbrium constants of surface complex formation between phosphate ions and surface sites, which can be used to calculate $\Delta \mathrm{H}$ and $\Delta \mathrm{S}$ in the adsorption process by using van't Hoff equation below.

$$
\ln \mathrm{K}=-\frac{\Delta H^{0}}{R T}+\frac{\Delta S^{o}}{R}
$$

With $\mathrm{K}$ stands for equilibrium constant, $\mathrm{T}$ for temperature (Kelvin), and $\mathrm{R}$ for gas coefficient. Based on the equation, graphs of $\ln \mathrm{K}$ vs $1 / \mathrm{T}$ is linier with the slope of $-\frac{\Delta H}{R}$ and intercept of $\frac{\Delta S}{R}$.

Referring to the arguments, this research was conducted to study the effects of temperature to the adsorption of phosphate ions by montmorillonite, to ascertain surface reactions and their equilibrium constants results from temperature variation. This research is also to determine the values of $\Delta \mathrm{H}$ and $\Delta \mathrm{S}$ on the adsorption of phosphate ions by montmorillonite.

\section{Methods}

Determination of Montmorillonite Surface Area. Montmorillonite samples were saturated by using $\mathrm{K}^{+}$ions, and its specific surface area was measured by using surface area meter NOVA 1000 which was $20.559475 \mathrm{~m}^{2} / \mathrm{g}$.

Adsorption Experiments. The experiments included 3 kinds of experiments; adsorption edge (adsorption as function $\mathrm{pH}$ ), adsorption isotherm, and acid-base titration. Each adsorption experiment was done in the temperature of $10{ }^{\circ} \mathrm{C}$, $30{ }^{\circ} \mathrm{C}$, and $50{ }^{\circ} \mathrm{C}$.

The adsorption edge was conducted to find out $\mathrm{pH}$ influence on the adsorption. Into $200 \mathrm{~mL}$ suspension of $50 \mathrm{~m}^{2} \mathrm{~L}^{-1}$ equilibrated using montmorillonite, $\mathrm{KOH}$ was added to reach the $\mathrm{pH}$ of the suspension about 10. Some amount of phosphate stock solution was added so the concentration of the phosphate is $0.1 \mathrm{mM}$. The suspension was then stirred for about 30 minutes by using magnetic stirrer, and sample was taken and put into well-capped test tube. $\mathrm{pH}$ of the suspension in reaction vessel was decreased by adding $0.1 \mathrm{M} \mathrm{HNO}_{3}$, and after another 30 minutes, $3 \mathrm{~mL}$ sample were taken and transferred to well-capped test tube. This experiment was repeated until the $\mathrm{pH}$ of the suspension reaches about 3. All samples in the well-capped test tube were being stirred-up for a day ( 24 hours), the optimum time obtained from kinetic adsorption. After that, all samples were being centrifuged and the filtrate was analyzed for free phosphate ions in solution.

Adsorption isotherm was conducted to find out the effect of phosphate concentration. The $\mathrm{pH}$ of $200 \mathrm{~mL}$ suspension of $50 \mathrm{~m}^{2} \mathrm{~L}^{-1}$ montmorillonite was adjusted to be $\mathrm{pH} 4$ and kept constant by adding $\mathrm{KOH}$ or $\mathrm{HNO}_{3}$. After that, 3 $\mathrm{mL}$ of solution stock of $0.01 \mathrm{M}$ phosphate whose $\mathrm{pH}$ has already been adjusted to $\mathrm{pH} 4$, added into suspension and let it equilibrates for the optimum time (24 hours, result from kinetic adsorption [6]. Sample was taken and put into well-caped test tube. Stock solution of phosphate, $5 \mathrm{~mL}$ was added again, and so on until total volume of stock solution added was $30 \mathrm{~mL}$. All samples in the test tube were stirred-up for 1 day, and then were centrifuged and the filtrate was analyzed for phosphate free concentration.

Acid and base titration were analyzed toward phosphate solution to determine the dissociative reactions, towards montmorillonite suspension to determine protonation and deprotonation of surface reactions, also towards suspension containing both montmorillonite and phosphate to find out surface complex reactions and their equilibrium constants. One hundred $\mathrm{mL}$ of $1 \mathrm{mM}$ phosphate solution was added by $\mathrm{KOH}$ to increase the $\mathrm{pH}$ to become 10 , and then equilibrated and titrated with $\mathrm{HNO}_{3}$ until $\mathrm{pH}$ reached 3.0. Every addition of certain amount of acid, the $\mathrm{pH}$ was monitored seriously until the changing less than $0.1 \mathrm{mV}$ per minute, a criteria which usually filled by 30-50 minutes.

Titration towards suspension containing montmorillonite clay mineral only, and towards phosphate-montmorillonite were carried out in the same methods. Suspension has to be stirred first for $18-24$ hours before it was titrated. Phosphate and montmorillonite concentrations were $1 \mathrm{mM}$ and $100 \mathrm{~m}^{2} \mathrm{~L}^{-1}$ respectively.

Determination of free phosphate ion concentration. Concentration of free phosphate ions can be determined by complexation with molybdenum [7]. Two $\mathrm{mL}$ of $10 \%$ sulphate acid and $1 \mathrm{~mL} \mathrm{5 \%}$ ammonium molybdate were added into sample and stirred-up for 5 minute. The samples were then measured by using Spectrophotometer UV-Vis at wavelength of 390 $\mathrm{nm}$. 
Data Analysis. Experiments data was modeled by using a computer software, GRFIT [8]. Data from these adsorption experiments on temperature $30{ }^{\circ} \mathrm{C}$ was modeled by Extended Constant Capacitance Model (ECCM) [6] whose parameters were used as fix parameters to model experimental data on the other temperatures, 10 ${ }^{\circ} \mathrm{C}$ and $50{ }^{\circ} \mathrm{C}$ to get the values of equilibrium constants at relevant temperatures. The model has been used in previous investigations [6, 9-15].

\section{Result and Discussion}

In general, parameters from the modeling at temperature of $30{ }^{\circ} \mathrm{C}$ [6] fit well to titration data at temperature of 10 and $50{ }^{\circ} \mathrm{C}$ (Figure 2-3) with full parameters are listed in Table 1, which means proposed reactions and their equilibrium constants from the modeling are good enough to explain the adsorption process. The modelling results was supported by adsorption kinetics [6], XRD diffractogram and IR spectrogram [15].

The model suggests four different results related to the surface of montmorillonite, e.i.

(a) concentration of active sites,

(b) surface capacitance,

(c) surface reactions: protonation-deprotonation and surface complex formation, and

(d) equilibrium constants of both surface reactions.

Temperatures affect only the equilibrium constants of the reactions both protonationdeprotonation and surface complex formation as given in Table 1. Therefore, the parameters of a, $\mathrm{b}$, and $\mathrm{c}$ were not affected by temperature and reported previously [6].

The reactions for surface protonationdeprotonation obtained from the modeling are given in Arabic numbers $1-3$ below [6].

1. $\mathrm{SOH}+\mathrm{H}^{+} \gtrless \mathrm{SOH}_{2}^{+}$

2. $\mathrm{SOH} \gtrless \mathrm{SO}^{-}+\mathrm{H}^{+}$

3. $\left[\mathrm{X}^{-}-\mathrm{H}^{+}\right]^{0}+\mathrm{K}^{+} \gtreqless\left[\mathrm{X}^{-}-\mathrm{K}^{+}\right]^{0}+\mathrm{H}^{+}$

Whereas, the reactions for surface complex formation from the modeling are listed in the following Arabic numbers 4-5.
4. $\left[\mathrm{X}^{-}-\mathrm{H}^{+}\right]^{0}+\mathrm{H}_{2} \mathrm{~L}^{-} \gtreqless\left[(\mathrm{XH})^{0}-\mathrm{H}_{2} \mathrm{~L}^{-}\right]^{-1}$
5. $2 \mathrm{SOH}+\mathrm{H}_{2} \mathrm{~L}^{-} \gtreqless\left[\left[\left(\mathrm{SO}^{-}\right)(\mathrm{SOH})\right]^{-}-\left[\mathrm{H}_{2} \mathrm{~L}\right]^{-}\right]^{-2}$ $+2 \mathrm{H}^{+}$

Where $\mathrm{SOH}$ represents $\mathrm{pH}$-dependently charged surface active sites and $\mathrm{X}^{-}$represents permanent negatively-charged sites of montmorillonite due to the isomorphous substitution. $\mathrm{H}_{2} \mathrm{~L}^{-}$is the symbol for $\mathrm{H}_{2} \mathrm{PO}_{4}^{-}$. The surface complex reactions numbered 4 and 5 above are the main reactions representing the process of adsorption of phosphate ions by montmorillonite for which $\Delta \mathrm{H}$ and $\Delta \mathrm{S}$ are calculated. Therefore, the suface complexation reactions are then called by reactions 4 and 5 respectively.

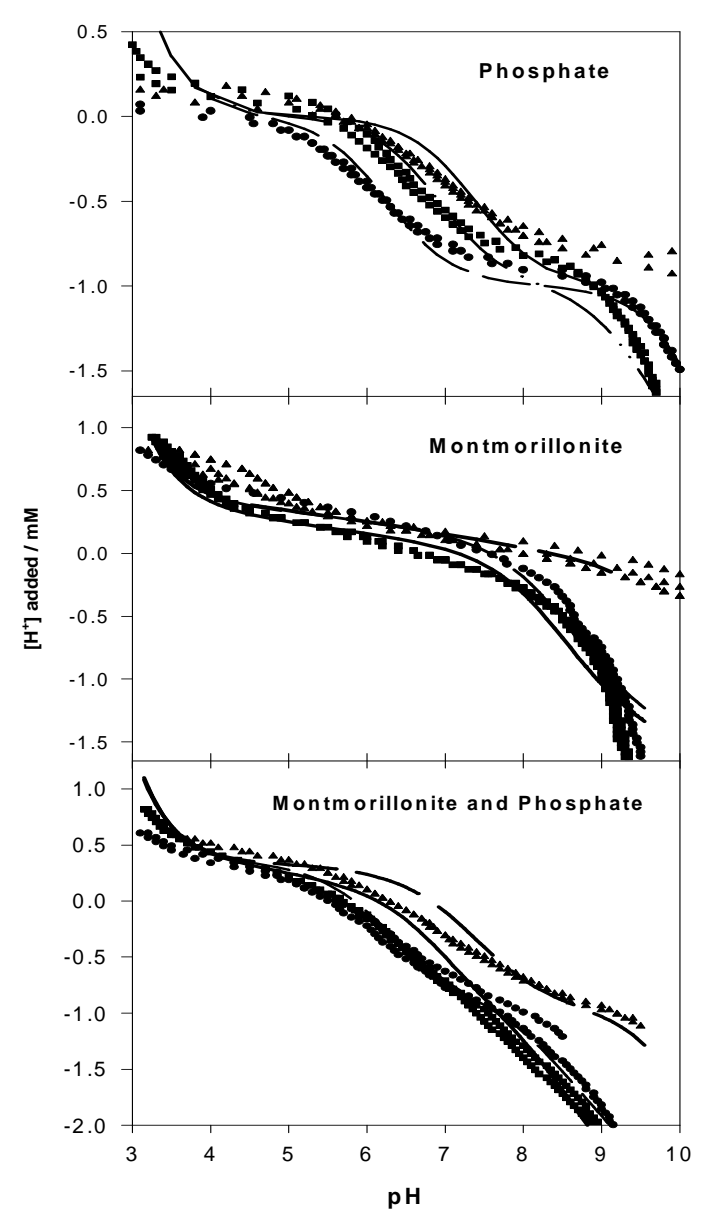

Figure 1. Acid-base titration to the systems at different temperatures: $(\boldsymbol{\Delta}) 10^{\circ} \mathrm{C},(\bullet) 30^{\circ} \mathrm{C}$, and $(\boldsymbol{\bullet}) 50^{\circ} \mathrm{C}$. The

lines were calculated using parameters as reported previously [6] and in Tables 1-2.

The equilibrium constants of the above mentioned reactions are listed in Table 1.

Table 1.Equibrium constants of surface reactions in different temperature calculated by ECCM

\begin{tabular}{rccc}
\hline No. Reactions & $\mathbf{1 0}^{\mathbf{}} \mathbf{C}$ & $\mathbf{3 0}^{\circ} \mathbf{C}$ & $\mathbf{5 0}^{\circ} \mathbf{C}$ \\
\hline & \multicolumn{4}{c}{$\mathbf{L o g} \boldsymbol{K}$} \\
$\mathbf{1}$ & 5,726 & 5,461 & 4,313 \\
$\mathbf{2}$ & -6.603 & $-6,501$ & $-5,579$ \\
$\mathbf{3}$ & 5,726 & 5,461 & 4,313 \\
$\mathbf{4}$ & -0.9455 & -0.4254 & -0.0393 \\
$\mathbf{5}$ & -6.396 & -3.624 & -2.356 \\
\hline
\end{tabular}


In addition, Figure 1 suggests that titration of phosphate solution at different temperatures shows different behaviour. Fitting of the titration data of phosphate solution gives thedeprotonation reactions:
6. $\mathrm{H}_{3} \mathrm{~L}$
7. $\mathrm{H}_{2} \mathrm{~L}^{-} \gtreqless \mathrm{H}_{2} \mathrm{~L}^{-}+\mathrm{H}^{+}$
8. $\mathrm{HL}^{-2} \gtreqless \mathrm{L}^{-3}+\mathrm{H}^{+}$

The parameters obtained from the model (Tables 1-2) and with other parameters of capacitance and site concentrations [6] were then used as fix parameters for adsorption edge data (Figure 2) and adsorption isotherm data (Figure $3)$.

Table 2. Equilibrium constants of phosphate dissociation at different temperature

\begin{tabular}{|c|c|c|c|c|}
\hline \multirow{2}{*}{$\begin{array}{c}\text { No. } \\
\text { Reac- } \\
\text { tion }\end{array}$} & & $\log K$ & & \multirow{2}{*}{ Ref. *) } \\
\hline & $10^{\circ} \mathrm{C}$ & $\begin{array}{c}3{ }^{\circ} \mathbf{C} \\
{[6]}\end{array}$ & $50^{\circ} \mathrm{C}$ & \\
\hline 6 & -1.900 & -2.000 & -2.100 & $\begin{array}{l}-2.143[16], \\
-3.875[17]\end{array}$ \\
\hline 7 & -7.386 & -6.260 & -6.293 & $\begin{array}{l}-7.201[16], \\
-7.208[17]\end{array}$ \\
\hline 8 & -18.272 & $\begin{array}{l}- \\
16.627\end{array}$ & $\begin{array}{l}- \\
16.493\end{array}$ & $\begin{array}{l}-12.377 \text { 16], } \\
-19.876 \text { 17] }\end{array}$ \\
\hline
\end{tabular}

Thermodynamic parameters were then calculated using van't Hoff equation based on the equilibrium constants obtained from the modeling. The thermodynamic parameters from the calculation are depicted in Table 3. Temperature affects the adsorption significantly. This can be seen from the experimental results both adsorption edge (Figure 2) and adsorption isotherm (Figure3). Effect of temperature to the adsorption has been reported, as the temperature can change the nature of sorbate, surface charges of sorbent, and reaction kinetics $[1-4,18,19]$.

Table 3. Thermodynamic Parameter in Adsorption Process of Phosphate Ion by Montmorillonite

\begin{tabular}{|c|c|c|}
\hline No. Reaction & $\begin{array}{c}\Delta \mathbf{H} / \\
\left(\mathrm{kJ} \mathrm{mol}^{-\mathbf{1}}\right)\end{array}$ & $\begin{array}{c}\Delta \mathrm{S} / \\
\left(\mathrm{J} \mathrm{K}^{-1} \mathrm{~mol}^{-1}\right)\end{array}$ \\
\hline 4 & 39.756 & 122.523 \\
\hline 5 & $3.765 \times 10^{-7}$ & $2.393 \times 10^{-2}$ \\
\hline
\end{tabular}

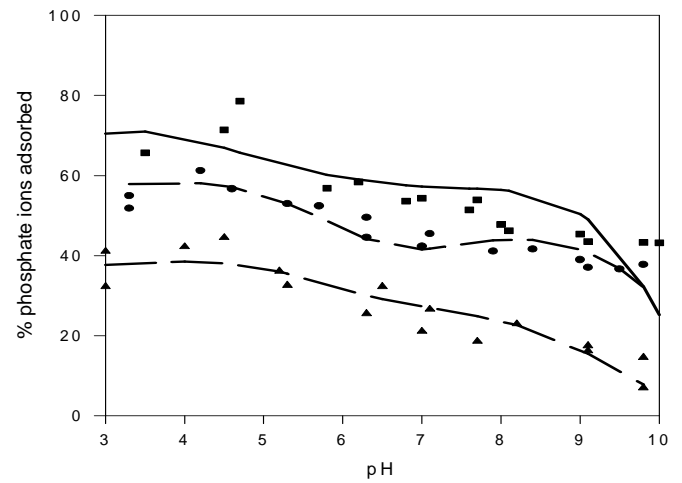

Figure 2. Effect of $\mathrm{pH}$ to the adsorption of $0.1 \mathrm{mM}$ phosphate ion by $50 \mathrm{~m}^{2} \mathrm{~L}^{-1}$ montmorillonite at temperature of $(\Delta) 10^{\circ} \mathrm{C},(\bullet) 30^{\circ} \mathrm{C}$, and $(\bullet) 50{ }^{\circ} \mathrm{C}$. The lines were calculated using parameters as reported previously [6] and in Tables 1-2.

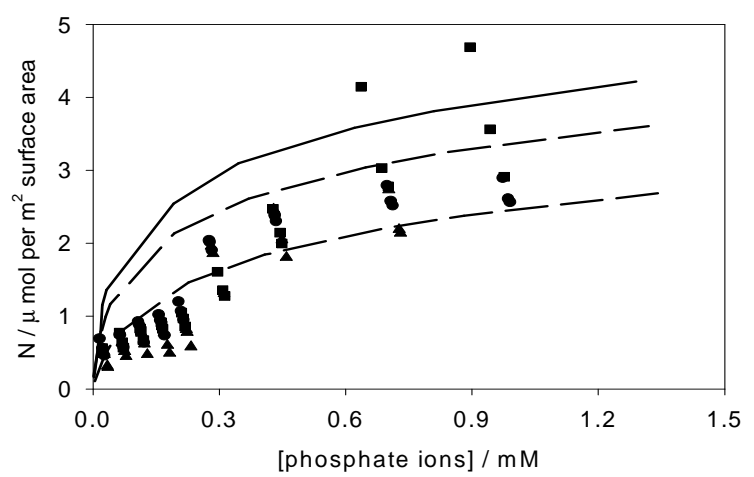

Figure 3. Isotherm Adsorption of phosphate by montmorillonite at $\mathrm{pH} 4$ and temperature $(\boldsymbol{\Delta}) 10^{\circ} \mathrm{C}$, (•) $30{ }^{\circ} \mathrm{C}$, dan $(\boldsymbol{\square}) 50{ }^{\circ} \mathrm{C}$. The lines were calculated using parameters as reported previously [6] and in Tables 1-2.

From this study, it can be seen obviously that chemical nature of sorbate is influenced by temperature. The distribution of phosphate speciation in the $\mathrm{pH}$ range of investigation is significantly different due to the temperature difference (Figure 4). Despite density and capacity of surface active sites may not be influenced by temperature, but equilibrium constants of montmorilonite surface protonationdeprotonation are affected significantly by temperature (Table 1). Therefore, at temperature range of this study, montmorillonite surface structure did not change, but surface affinity to the cations, anions, or protons that are available in the system is affected by temperature, and so surface reaction equilibrium is significantly influenced by temperature. 


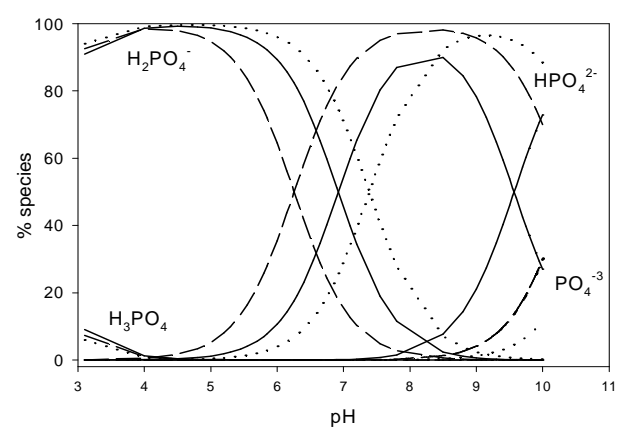

Figure 4. Distribution of phosphate speciation at different temperatures of $(\cdots \cdots \cdots \cdot) 10$ ${ }^{\circ} \mathrm{C},(---) 30{ }^{\circ} \mathrm{C}$ and $(-) 50{ }^{\circ} \mathrm{C}$, calculated with the parameters listed in Table 2.

This study also found that adsorption and desorption increased significantly due to the increase of temperature, which shows that surface complex formation is endothermic. $\Delta \mathrm{H}$ value is a total amount of energy barrier that must be overcome by a reaction [20]. Large value of $\Delta \mathrm{H}$ $\left(39,756 \mathrm{~kJ} \mathrm{~mol}^{-1}\right)$ for the reaction 4 (Table 3) suggested that reaction is endothermic, at which the reactions need energy to change reactants to become products. $\Delta \mathrm{H}$ is related to activation energy $(E a)$ which is represented by the equation, $E \mathrm{a}=\Delta \mathrm{H}+\mathrm{R} \mathrm{T}\left(\mathrm{T}=25^{\circ} \mathrm{C}\right)$.

Scheckel and Sparks [21] found that the activation energy was not different for different temperature. The value of activation energy is calculated by using the formula shown above at $\mathrm{T}$ $=25{ }^{\circ} \mathrm{C}$. This means that in this adsorption process, the value of $E \mathrm{a}$ is $42.234 \mathrm{~kJ} \mathrm{~mol}^{-1}$ for reaction 4 and $2,478 \mathrm{~kJ} \mathrm{~mol}^{-1}$ for reaction 5 .

Kinetic sorption where some phosphate was not being desorbed easily from montmorillonite surface indicated that interaction between phosphate and $\mathrm{X}^{-}$surface sites that binds proton at low $\mathrm{pH}$ values $(\mathrm{XH})$ is strong enough [6]. Strong energy is needed by $\mathrm{X}^{-}$sites to get partial desolvation in a protonation process, in which $\mathrm{H}^{+}$ exchanges $\mathrm{K}^{+}$or cation saturated $\mathrm{X}^{-}$active sites, to which phosphate ions are then bound. As a result, interlayer regions of montmorillonite decrease significantly [15].

Different observation was found on reaction 5. $\Delta \mathrm{H}$ value for this reaction is very small $\left(3.765 \times 10^{-7} \mathrm{~kJ} \mathrm{~mol}^{-1}\right)$. However, since the $\Delta \mathrm{H}$ value is positive, so the reaction is endothermic. This indicates that hydrogen bond in surface complex formation in the reaction $\mathbf{5}$ is easily desorbed. As a consequence, kinetic sorption showed that some phosphate which has been adsorbed by montmorillonite can be desorbed easily [6].

$\Delta \mathrm{S}$ value is an indication whether reaction occurs through associative or dissociative mechanism. If the value of $\Delta \mathrm{S}>-10 \mathrm{~kJ} \mathrm{~mol}^{-1}$, it generally implies a dissociative reaction mechanism [21]. It is given in Table 3 that entropy value is positive for both reactions $\mathbf{4}$ and 5. The values of $\Delta S$ is large enough for the reaction $\mathbf{4}$, but small for the reaction $\mathbf{5}$. These $\Delta S$ values in this study indicates that surface compexation reactions in the adsorption of phosphate ion by montmorillonite occurs through dissociative mechanism. At reaction $\mathbf{4}, \mathrm{X}^{-}$ protonation reaction is a mechanism step which determines the reaction, in which $\mathrm{K}^{+}$ions dissociates into solution and is replaced by proton $\mathrm{H}^{+}$, which finally interacts phosphate ions. While in the reaction $\mathbf{5}$, dissociation occurs when $\mathrm{SOH}$ active sites is deprotonated to release proton $\left(\mathrm{H}^{+}\right)$ and then interacts phosphate ions.

Besides that, $\Delta \mathrm{S}$ value is generaly dealing with desolvation process when $\mathrm{K}^{+}$ions are released into solution by $\mathrm{X}^{-}$permanentlynegative charged sites. Similar argument was reported by Fokkink [22] that entropy of $\mathrm{Cd}(\mathrm{II})$ metal ion hydration of about $100 \mathrm{~J} \mathrm{~K}^{-1} \mathrm{~mol}^{-1}$ was obtained when the metal ions were adsorbed.

Value of $\Delta \mathrm{G}$ for a reaction can be calculated by using equation of $\Delta \mathrm{G}=\Delta \mathrm{H}-\mathrm{T} \Delta \mathrm{S}$, from which the values are small positive (for the reaction 4) and large positive (for the reaction 5). This indicates that surface complex formation in the adsorption of phosphate ions by montmorillonite can occur if energy is given to the system. The energy that is needed for the complex formation in reaction $\mathbf{4}$ is smaller than that in reaction $\mathbf{5}$.

\section{Conclusion}

The values of $\Delta \mathrm{H}$ for the surface complex reactions numbered $\mathbf{4}$ and $\mathbf{5}$ are 39.756 and $3.765 \times 10^{-7} \mathrm{~kJ} \mathrm{~mol}^{-1}$ respectively. Both reactions have positive $\Delta \mathrm{H}$ values which mean the reactions are endothermic. The energy needed by $\mathrm{X}^{-}$sites in the reaction $\mathbf{4}$ is mainly for partial desolvation in protonation process of the sites, on which $\mathrm{H}^{+}$ ions replaces $\mathrm{K}^{+}$or other cations on the surface, which then interacts phosphate ions by hydrogen bonding. Smaller $\Delta H$ values in the reactions indicates that hydrogen bond in complexes formation of reaction numbered $\mathbf{5}$ is easily released. $\Delta S$ value for the surface $\mathbf{4}$ and $\mathbf{5}$ are 122.523 and $2.393 \times 10^{-2} \mathrm{~J} \mathrm{~K}^{-1} \mathrm{~mol}^{-1}$, respectively. 
$\Delta \mathrm{S}$ values in both reactions which are larger than $-10 \mathrm{~kJ} \mathrm{~mol}^{-1}$ indicates that both reactions occurs in dissociative reaction mechanism.

\section{Acknowledgement}

This article was taken from the report of Fundamental Research in the year of 2007, funded by DP2M-DIKTI, DGHE, Ministry of Education and Culture of Republic of Indonesia, with contract No. 036/SP2H/PP/DP2M/III/2007. Writers would like to thank to DP2M.

\section{Reference}

[1] Benjamin, M.M. and Leckie, J.O. (1981). Competitive Adsorption of $\mathrm{Cd}, \mathrm{Cu}, \mathrm{Zn}$, and $\mathrm{Pb}$ on Amorphous Iron Oxyhydroxide, Journal of Colloids and Interface Sciences, 83: 410-415.

[2] Barrow, N. J. (1986). Testing a Mechanistic Model. II The Effect of Time and Temperature on the Reaction of Zinc with a Soil, Journal of Soil Sciences, 37: 277-283.

[3] Johnson, B. B. (1990). Effect of pH, Temperature, and Concentration on the Adsorption of Cadmium Goethite, Environmental Science and Technology, 24: 112-117.

[4] Brady, P.V., Cygan, R.T., and Nagy, K. L. (1996). Molecular Control on Kaolinite Surface Charge, Journal of Colloid Interface Science. 183: 1-7.

[5] Mc Cash, E. M. (2001). Surface Chemistry. University of York and Sentec Ltd, Cambrige: Oxford universty Press

[6] Ikhsan, J., Endang W. LFX., dan Sunarto. (2012). Studi komparasi sorpsi ion fosfat oleh Geothite dan montmorillonite, Proceeding: National Seminar, UNS SoloIndonesia, 476.

[7] Kabayama, M., Kawasaki, N., and Nakamura, T., Tokimoto, T., and Tanada, S. (2004). Adsorption of Phosphate Ions from Sea Water by Use of Surface-Modified Boehmite, Surface Scientific. 25(8): 499503.

[8] Ludwig, C. (1992). GRFIT - A Computer Program for Solving Speciation Problems: Evaluation of $s$, Concentration and Other Physical Parameters. Switzerland: University of Berne

[9] Ikhsan, J., Widjajanti LFX, E., and Sunarto. (2006) Study of Reaction Mechanisms on the Adsorption of 9-Aminoacridine by Montmorillonite, Proceeding: International Conference on Mathematics and Natural Sciences, ITB Bandung.

[10] Ikhsan, J., Wells, J.D., Johnson, B.B. and Angove, M.J. (2005). Surface Complexation Modeling of the Sorption of $\mathrm{Zn}$ (II) by Montmorillonite, Colloids and Surfaces A: Physicochemical and Engineering Aspects, 252, 33-39.

[11] Ikhsan, J., Angove, M.J., Wells, J.D. and Johnson, B.B. (2005). Surface Complexation Modeling of the Sorption of 2-, 3-, and 4aminopyridine by Montmorillonite, Journal of Colloid and Interface Science, 284(2): 383-389.

[12] Angove, M.J., Fernandes, M.B. and Ikhsan, J. (2002). The Sorption of Anthracene onto Goethite and Kaolinite in the Presence of Some Benzene Carboxylic Acids, Journal of Colloid and Interface Science, 247: 282-287.

[13] Ikhsan, J., Angove, M.J., Johnson, B.B. and Wells, J.D. (2005). Cosorption of Zn(II) and 2-, 3-, or 4-aminopyridine by Montmorillonite, Journal of Colloid and Interface Science, 284(2): 400-405.

[14] Ikhsan, J., Wells, J.D. and Johnson, B.B. and Angove, B.B. (2005). Sorption of 3-amino1,2,4-triazole and $\mathrm{Zn}(\mathrm{II})$ onto Montmorillonite, Clays and Clay Minerals, 53(2): 137-142.

[15] Ikhsan, J., Widjajanti LFX, E., and Sunarto. (2007). Memahami Proses Sorpsi Ion Fosfat oleh Goethite dan Montmorillonite, Laporan Penelitian Fundamental, Lembaga Penelitian UNY.

[16] Silberberg, M.S., (2000). Chemistry: The Molecular Nature of Matter and Change, 2nd edition, Boston: Mc.Graw Hill, 776.

[17] Anonym, http://inorg-phys.chem.itb.ac.id/ wp-content/uploads/2007/04/bab-9-10.pdf, accessed on October 29, 2008.

[18] Yadava, K.P., Tyagi, B.S, ang Singh, V.N. (1991). Effect Temperature on the Removal of Lead(II) by adsorption on China Clay and Wollasonite, Journal of Chemical Technology and Biotechnology, 51: 47-52.

[19] Brady, P.V. (1994). Alumina Surface Chemistry at 25, 40, and 60 C, Geochimica et Cosmochimica Acta. 58, 1213.

[20] Jencks, M. P. (1969). Catalysis in Chemistry and Enzymology, McGraw-Hill, New York.

[21] Scheckel, K. G. and Sparks, D. L. (2001). Temperature Effects on Nickel Sorption 
Kinetics at the Mineral-Water Interface, Soil Sci. Soc. Am. J., 65: 719-722.

[22] Fokkink, L.G.J., de Keizer A., and Lyklema, J. (1990). Temperature Dependance of Cadmium Adsorption on Oxides. 1. Experimental Observations and Model Analysis, Journal of Colloid and Interface Science, 135: 118-122. 